\title{
A Convivial Journey: From Diversity in Istanbul to Solidarity with Refugees in Denmark
}

\section{Deniz Neriman Duru}

\section{INTRODUCTION}

This chapter probes the concept of convivial solidarity by narrating my analytical journey from ethnographic research on conviviality and diversity in Istanbul, to research on solidarity with the migrants and refugees living in Denmark. In the first part, I briefly describe how I engaged with the concepts of multiculturalism and coexistence before I went to conduct fieldwork in Istanbul, and explain how I came to use the concept of conviviality while analysing my ethnographic data (Duru ,2015, 2016). In the second part of the chapter, I present the EU Horizon 2020 project on transnational solidarity with migrants and refugees, 'Transnational Solidarity in times of crisis' (Duru et al. 2016), which employed altruistic and mutual solidarity as concepts without using the concept of convivial solidarity in the deductive design of mapping solidarity initiatives of civil society organisations. Nonetheless, after conducting the interviews with

\footnotetext{
D. N. Duru $(\bowtie)$

Department of Communication and Media, Lund University, Lund, Sweden e-mail: deniz.duru@kom.lu.se

(C) The Author(s) 2020

O. Hemer et al. (eds.), Conviviality at the Crossroads, https://doi.org/10.1007/978-3-030-28979-9_7
} 
the representatives from the civil society, in the inductive analysis stage of the material I realised that the interviewees referred to what I conceptualised as convivial solidarity, which is a new concept that I have developed (which appeared first in Duru et al. 2016). In this chapter, I tentatively use this concept to open a discussion about how convivial solidarity explains what cannot be described by the concepts of mutual and altruistic solidarity nor by conviviality.

\section{PART i: Diversity in Istanbul \\ Pre-fieldwork Literature Review}

When starting my doctoral studies in Social Anthropology at the University of Sussex in 2008, I wanted to understand how people of different backgrounds (including but not limited to ethnicity, religion, and social class) live together in diverse societies. While the Balkans and Turkey have long been pathologised as places of ethnic turmoil (Todorova 1997) and un-mixing of people (Hirschon 2003), I investigated Burgaz, one of the Princes' Islands of Istanbul, where people of different ethnic, religious and socio-economic backgrounds have been living for centuries. Peace there did not break down despite pogroms in 1955 (where violence took place in other Princes' Islands and parts of Istanbul (see Güven 2006; Kuyucu 2005), Turkification policies, the worsening relations between Turkey and Greece over Cyprus, and the Turkish invasion of Cyprus (Akgönül 2007; Güven 2006). How do, and how did people from different backgrounds live together? What do they do to manage tensions? What makes people bond to each other? How can we describe, explain and conceptualise this?

In the academic literature I had read prior to my fieldwork (before 2009), multiculturalism, coexistence, cosmopolitanism and super-diversity were used as theoretical frameworks to describe diverse societies and living with difference. Multiculturalism and coexistence theories had a tendency to divide societies into ethnic and/or religious compartments. In my noncommunitarian approach in researching diversity, I built on Cowan (2006), who criticised the communitarianism of Joppke and Lukes' (1999) "mosaic" multiculturalism. Also, theories on post-conflict coexistence (Phillips 1996; Gidron et al. 2002; Dayton and Kriesberg 2009) postulated the existence of ethnic and religious groups as given and generally saw conflicts as triggered by ethnic and religious differences. In a post-Yugoslav context, coexistence approach assumes that the differences and identities of e.g. 
Serbs and Bosnians have always existed as such, disregarding/forgetting the realm of everyday life, and common ways of living shared in the same neighbourhoods over centuries. A person is not only a Bosnian or a Serb but a komsija (from komş - neighbour in Turkish), a friend, a hairdresser, a grumpy woman or a chatterbox man. Both multiculturalism and coexistence theories focus on culture as difference and undermine what people share in common. The culture as difference, or "culture as mosaic" approach (criticised in Eriksen 2001) posits boundaries between groups as it homogenises and essentialises 'their culture'.

The concept of cosmopolitanism as I encountered it in the literature I read before 2009 referred to the individual practice of engagement of the 'self' with an 'Other' (Hannerz 1990), and hence did not help me theorise the sense of collectivity or unity I encountered in the field. ${ }^{1}$ Finally, the theory of super-diversity (Vertovec 2007) recognised that differences are diversified, that we should go beyond the categories of ethnicity and religion, and explore and understand the complexity of diversity. Nonetheless, for me it was more helpful as a way of asking critical questions driven by my ethnographic material, rather than for conceptualising how it is to live in diversity.

I conducted fieldwork on Burgaz for 14 months in 2009-2010. As an anthropologist, I believed that ethnography was the valid methodology to understand what occurs on the ground (Cowan 2006), and what people actually do. I focused on the 'multicultural' as an adjective to describe plurality on the ground-in opposition to multiculturalism as a political project, i.e. as top-down approaches (characteristic for policies, politicians, political theorists) that focused on how people should live together and what policies or laws should be used in order to manage diversity. Thus, an in-depth, ethnographic exploration of everyday practices of living together in diversity was my response to Grillo's call (2007) for anthropologists to go beyond the normative analysis of multiculturalism and to move away from the philosophical reflections at an abstract or institutional level.

\section{Post-fieldwork Analysis: Conceptualising Conviviality}

My fieldwork revealed that people from different backgrounds form relations based on common interests, lifestyles, tastes, and also in order to fight for a common cause (Duru 2013). While the lens of coexistence and toleration search for cohesion and conflict based on ethnic and religious differences and implies 'living with difference', in Burgaz, I could see 
what people have in common: shared ways of living and acts of solidarity. I paid attention to the everyday living and to how the islanders represented/articulated their pluralism by the words and metaphors/allegories they used. The islanders' conceptualisation of their diversity challenged Taylor's (1992) and Kymlicka's (1995) approaches to recognition of differences as a basis to secure equality and rights, and Joppke and Luke's (1999) description of society in the form of mosaic. As stated by the islanders, the diversity in Burgaz was not about the identity of different groups. People's ethnicity and religion were recognised but what was important was the bonding, conviviality, intimacy and solidarity between individuals, and their collective sense of belonging in Burgaz. Similar to Valluvan (2016: 218), the islanders were able 'to invoke difference, whilst avoiding communitarian, groupist precepts'. The Burgaz islanders described their diversity as 'marbling' (ebru in Turkish) in opposition to 'mosaic' where the patterns have distinct borders and are hence more vulnerable to destruction. In $e b r u$, even though patterns still keep their distinctiveness, their boundaries fuse into each other and form a more solid picture as a whole (Duru 2015).

I wanted to look for concepts that could explain cohesion, solidarity, tension, and conflict, but were not based on established views of coexistence/toleration. Rather, I wanted to find concepts to explain these phenomena which reflected the 'marbling' view of diversity that I experienced in Burgaz. I came across Overing and Passes' (2000) work of conviviality in Amazonia, where they had developed conviviality, from the Spanish word 'convivencia', that refers to joint/shared life. These authors argued that conviviality does not only comprise peaceful moments but also tensions, management of conflicts that are grounded in the sharing of daily life. In my thesis (Duru 2013) and further publications (Duru 2015, 2016), I used conviviality as a framework to overcome the pitfalls of multiculturalism and coexistence. Building on Chau's (2008) sensorial production of the social, and Ring's (2006) and Overing and Passes' (2000) management of everyday tensions, I described conviviality as an embodiment of diversities and diverse senses (Duru 2016). Islanders attend each other's religious places, feasts, parties, and funerals; experience the island with their senses, while swimming and fishing in the sea, smelling and touching the mimosas, eating the berries and the green bitter plums of the trees, watching the sunset and the sunrise; they also fight with each other about who gossiped from behind whom, or who beats the carpet and lets the dust fall on the neighbour below. All of these pleasures, conflicts, and tensions make the islanders 
feel that it is their island, creating a sense of unity and a strong sense of belonging to the island that overrides ethnic, class, and religious identities of individuals at times of crisis and despite political tension in Turkey. At times of crisis and hardship, survival of the community of Burgaz islanders takes priority over individual or group differences. Conviviality as I saw it in Burgaz was neither about fleeting encounters or courtesy (see Nowicka, Chapter 2 in this volume), nor only about collaboration; the communal bonding led to the survival of the community at critical times.

After completing the dissertation, I moved on to post-doc projects on cross-border practices, the physical and virtual mobility of Turkish migrants in Europe, and - most recently - to the project on civil society actors' solidarity with refugees and migrants. My interest in conviviality was set aside. However, when I collected the qualitative empirical material, conducting interviews with civil societies that support migrants and refugees in Denmark, their perceptions on solidarity made me rethink what I knew about conviviality. In the project I present in more detail below, convivial solidarity emerged as a concept I found suitable for describing civil society organisations' solidarity initiatives and actions with refugees in Denmark in 2016 .

\section{Part 2: Convivial Solidarity With Refugees IN DENMARK}

\section{Research Design and Methods}

In 2014-2015, I was a part of a consortium made of researchers from eight European countries $^{2}$ in a Horizon 2020 project on Transnational Solidarity, where we aimed to explore solidarity initiatives towards vulnerable groups (migrants and refugees, ${ }^{3}$ disabled people and unemployed people) during the recession that followed the 2008 financial crisis. The project was designed prior to the peak of asylum seeker arrivals in 2015 , while the data collection took place mostly in 2016 and collided with the emergence of many 'Refugee Welcome' initiatives in different parts of Europe. These initiatives were referred to by Glick Schiller (2016) as 'convivial practices' that ranged from demonstrations at train stations, to welcoming and providing temporary shelters, food and support, all with the aim of countering the anti-refugee discourses and restrictive migration policies. The project investigated legal and constitutional solidarity (Duru et al. 2018), grassroots, and small civil society organisations' solidarity activities 
and initiatives (Duru et al. 2016), and public perceptions on solidarity. A quantitative survey was employed to explore individual responses and perceptions on solidarity and mediated representations in one part of the project, and responses of solidarity in the news media and social media in the other. Each national partner had a leading role in a work package or an event. For some work packages such as the ones on civil society and on the media, all national teams had to collect and analyse the national data as designed by the leading team. The data I refer to in this section comes from the work package on civil society initiatives.

Implementing a mixed-methods design, this work package first mapped the existing practices regarding what kinds of solidarity actions were provided by civil society as presented on their online websites, through a hub search on the internet. We identified hubs/subhubs through keyword searches (refugee, migrant, asylum combined with organisation, association, network, initiative), which contained a large number of links (total of 267) connecting to the websites of civil society organisations supporting migrants and refugees. These hubs/subhubs were retrieved and exported to excel in the form of links to civil society organisations' websites by search engine experts. We then randomly selected 100 organisations and social movements that had at least one transnational solidarity characteristic such as support, activity and beneficiaries beyond national borders, or international partners. A codebook was prepared by the team responsible for mapping the transnational civil society initiatives, and deductive coding was applied in the eight countries listed above. Coders' training and inter-coder reliability tests were done in the beginning, middle, and towards the end of the data collection process.

From those hundred coded transnational solidarity organisations (TSOs), we sampled/selected ten small NGOs, charity organisations, grassroots movements, and protest groups within the field of migration and refugee support. Each national team interviewed one representative from each of the ten sampled TSOs in each partner country. They were asked about their role and experience in the TSO, their views on how the crises affected the solidarity actions, the challenges faced, and their reflections on solidarity actions. I conducted ten interviews in Copenhagen between August and October of 2016. Even though I aimed for a gender balance, the sample of interviewees was dominated by women $(8$ women and 2 men). Nonetheless, there was a diversity of age: 3 young, 4 middle-aged, and 3 informants in their late 70s. Many of the informants only started to work in their specific organisations within the last couple 
of years. Some were involved as volunteers, others had a higher degree of involvement such as management committee members, chairpersons, or founders. I did inductive coding during the qualitative analysis in order to explore approaches to and types of solidarity from the perspectives of our informants. Before I explore the empirical material, in the next section I will establish the sociopolitical context in Denmark in regard to incoming refugees and the situation of migrants in the country.

\section{Danish Context: In Between Civic Initiatives of Solidarity and Hostility Towards the Refugees}

Following the economic recession of 2008 and the increasing number of refugees arriving in Europe in 2015, European solidarity has been challenged with respect to the shared responsibilities of accommodating refugees and providing humanitarian support to other parts of the world (Federico and Lahusen 2018: 11). When state support was insufficient or cut down in some countries, the need for more support triggered many civil society actions both in the form of civic responses at the grassroots level, as well as increased formalised and organised support.

Even though Denmark has been relatively little affected by the financial crisis, the civil society sector experienced financial cuts and retrenchment. The building blocks of Danish society are its strong welfare state, popular trust in state institutions, and solidarity among its citizens, who see work and volunteering as an important part of the Danish identity (Henrik et al. 2013; Jöhncke 2011). In addition to the private donors and volunteers, the Danish state also supports civil society organisations through tax exemption. However, as an outcome of the financial crisis, the government at the time of the research and its predecessor both restricted benefits and support for migrants and refugees, and decreased the funding and resources of the civil society organisations. According to Gammeltoft-Hansen (2017), Denmark used policies of deterrence to discourage asylum seekers from applying in Denmark. The government at that time was supported by the Danish People's Party, which amassed the second largest number of votes in the 2015 elections and held an anti-immigrant agenda. Social benefits in the form of financial support for the refugees was cut in half, and it has gotten harder and harder to get refugee status and to obtain Danish citizenship. This situation created a twofold change in the Danish society. On the one hand, migrants and refugees were threatened by anti-immigrant discourses in the mass media, social media and in daily life. For instance, 
my interviewees who worked with Muslim beneficiaries pointed out that it had never been easy to be a Muslim living in Denmark and that the populist and anti-immigrant tone of the politicians and the dominant negative stereotyping of refugees in the media brought more threats to the Muslim population. One interviewee who offered physical and health education to Muslim women who suffered from some disability and/or health problems narrated in the interview ${ }^{4}$ :

In the first place, it started many years ago. We (Danes) wanted people to come and do bad work in Denmark and they came with their families (...) We should have said (to them): "you don't live (here) as in Pakistan or Turkey, you must learn about Danish society, because you live in Denmark" (...) Many who came at that time, did great work here and still do. Then we hear about people who make problems, and just get money from the social system. And now the rules are that it is very difficult to get any money. It is not as easy to live in Denmark as it was 30 years ago. The laws are very tightened up. (...) There have been many politicians who said: "They misused Denmark!", there have been many parties, Dansk Folkeparti, has been very good since the nineties (in saying) "We have to stop this (migration) because they are eating all our bread. They are taking our country. They have to go out. They are stealing from Denmark!" Uuuf. There are many people here who have done a lot of work for Denmark. This we forget. (Mette)

On the other hand, this harsh situation made more and more people volunteer and join civil society organisations in order to counter the harsh anti-immigrant tone and to fight the restrictions and hardship that refugees and migrants face. As stated by Stig:

The 'refugee crisis', or what you want to call it, has impacted that there has been more people and more volunteers, because I myself, would not have been a volunteer, you know, without hearing about these things and how we treat (immigrants), I have always been opposed to the way we treat immigrants but I have not known how to do anything or I have not been wired up enough to go out and seek to do anything. (Stig)

The incoming asylum seekers had thus rather been choosing to apply in neighbouring Sweden, which offers better conditions for accommodating them. Denmark also encouraged this by not controlling its borders, and letting the refugees pass through and reach Sweden where they were registered. Nonetheless, when Sweden implemented border controls between 
itself and Denmark in November 2015, many refugees had to remain in Denmark and hence their numbers increased from around 5000 in 2010 to around 20,000 in $2016 .{ }^{5}$ It was in this sociopolitical context that I conducted interviews with transnational civil society organisations' representatives in the summer of 2016.

\section{Convivial Solidarity as a Concept}

In the design of the quantitative part of the research, we built on the notions of mutual and altruistic solidarity, which are not mutually exclusive concepts. Altruism includes both the intent and behaviour that ranges from philanthropy, generosity, and volunteering with the aim to benefit others (Jeffries 2014). Solidarity refers to intergroup interaction, when people bond together and unite over common goals (Jeffries 2014). Solidarity thus can be in the form of in-group cooperation and can be mutual, where there is a self-interested reciprocal exchange among the people who engage with it (Bruni 2008). In our sample, those we identify to promote mutual solidarity are those who offer group empowerment/support, such as a Muslim youth organisation that helps Muslim youth. Weiss and Peres (2014) would describe this kind of mutual solidarity as 'soft altruism', which implies mutual care and reciprocity (the solidarity actions will benefit the self/ego), in opposition to 'hard altruism' (which they find impossible to apply to real life), when the self/ego has to be destroyed/annihilated in order to help others. Weiss and Peres (2014) are critical of the dichotomy between 'hard altruism' and 'soft altruism', and hence criticise political theorists and philosophers who conceptualised altruism and ego/egoism as mutually exclusive by arguing that there is egoism in altruism and vice versa. Nonetheless, in both mutual and altruistic solidarity, there is always a self in relation to another. Altruistic solidarity stresses the difference between the helper and the one that is helped and implies that the helper/volunteer is separated/different from the ones that are helped, such as when a nondisabled person is helping a disabled one.

Convivial solidarity differs from mutual and altruistic solidarity by ontologically not separating the self from the other. Convivial solidarity is a collective work in order to fight for a common aim and to find solutions for a common concern in a non-communitarian way without separating/classifying people by ethnicity, religion, citizenship, or nationality. 
Hence, in the situation of solidarity enactment there is no separation or hierarchy between the refugees, asylum seekers, and people who engage in solidarity activities. Convivial solidarity is my construct, referring to practices which include, (1) face-to-face social interaction, (2) a sense of common humanity (Glick Schiller 2016) emphasised by those who engage with it, and (3) a normative drive towards fighting for equal rights, (such as aiming to change asylum and migration policies). While conviviality refers to day by day living together, convivial solidarity inspires the people involved in possible future convivial living. When there is a situation of tension or crisis (e.g. concerning the high number of incoming refugees), convivial solidarity aims to 'solve' the situation and show support by the means of convivial practices. Crisis situations catalyse people's engagement in convivial solidarity, which is performed by civil society organisations and citizens, with a normative aim for convivial living.

I coded the websites of Danish civil society organisations in order to get information on what types of solidarity activities are performed, their aims/goals, and the route chosen by the civil society sector to achieve these aims. The quantitative results signalled to me that the majority of the solidarity actions were aiming to create a more inclusive society, trying to promote better communication and understanding for everyone. These solidarity actions largely chose direct contact in the form of face-to-face interactions, which made me think about the convivial tendency of civic actions that aim to create a sense of collectivity. The quantitative results showed that of the organisations surveyed, most disseminate information because they would like to raise awareness $(86 \%)$, on the difficulties refugees and migrants face and the conditions at the asylum centres. Most $(85 \%)$ of the organisations promote social exchange, direct contact, and integration in the society. $83 \%$ fight discrimination and promote equal participation in society, and $81 \%$ aim to increase tolerance and mutual understanding. They do so by doing face-to-face direct actions and solidarity activities $(84 \%)$, which include providing basic/urgent needs (79\%), and organising social and cultural activities (50\%).

In terms of direct actions/solidarity activities, they volunteer in the asylum and detention centres and spend their time with refugees and asylum applicants, teaching them Danish, gathering the paperwork they need, and engaging in creative activities (painting, drawing) to communicate and to relieve their stress. Basic/urgent needs comprise food, accommodation, clothing, medical and psychological help and support, human rights, legal 
advice, and language lessons. A smaller number of the selected organisations have a clearly stated political agenda on their website, with the aim of changing the system $(31 \%)$, policy reform $(30 \%)$, lobbying $(24 \%)$, collective protest action (14\%), and changing the government $(9 \%)$ or taking the legal route $(21 \%)$ (e.g. challenging Danish asylum policy through the courts, providing legal assistance to migrants). Nonetheless, in the interviews I conducted I came across a wide spectrum of political engagement, ranging from raising awareness, dissemination of information regarding the situation and conditions of asylum in order to fight the anti-immigrant rhetoric and attitudes, to protesting and lobbying for policy change (Duru et al. 2016: 131). This also made me think that convivial solidarity can include a wide range of political engagement.

I came to conceptualise convivial solidarity while I was analysing the semi-structured interviews conducted with the representatives of ten TSOs (which were sampled from the quantitative coding), particularly their statements about the solidarity activities and initiatives that their organisations were engaged in. I asked the representatives about their involvement with the organisation as well as what solidarity actions they did in their organisation, whether they took new initiatives, which other organisations they collaborated with, what they did differently compared to other organisations, and how they reflected on particular solidarity actions. In the following, I illustrate what I see as convivial solidarity, with the quotes taken from the interviews. Many interviewees mentioned that their organisations engage in face-to-face activities such as giving one-to-one Danish lessons and offer social activities ranging from dance and health classes, social hangouts, painting and drawing activities, to having coffee and tea together. Stig-a male volunteer in his late twenties who had just finished his Masters' degree in digital communication and IT and volunteered in a TSO which did creative activities at one of the asylum centres ${ }^{6}$ in Denmark, spoke about the purpose of his organisation and the activities they do.

The main purpose is that we generate some value in the daily life of the inhabitants of the camp. Our focus is creative things, to paint, draw, cut something in cardboard. Last week, one of the guys (asylum seeker) started an event, (...) a piece of wood, with some faces painted on, and the inhabitants could take spray and spray on it and they will be put on the fence of (the asylum centre) to create some life. Different things... But mostly creative. We don't force anyone to do anything, sometimes people just come in, sit and talk and have some coffee. 
That's fine as well, but the focus is on generating some value with creative things (...). (Stig)

As asylum seekers are 'locked in' the asylum centres and are separated from the Danish society, some of the organisations (like the one where Stig volunteers) show convivial solidarity with the asylum seekers to help them organise a daily life. Here, creativity is the realm of non-hierarchical relations. Social activities, ranging from having coffee to drawing, playing football, and sewing workshops are seen as providing daily life content that has value and meaning. These activities are not 'practices of conviviality' because the asylum seekers are separated from the Danish society and hence do not live together day by day, but they are 'convivial practices' that aim to generate meaning and a daily life together with the volunteers and the asylum seekers in a limited time and space. The following quote explains how the stress of waiting for a decision or receiving a rejection detaches the asylum seekers from an agreeable daily life:

Some days the tensions are really high at (name of the asylum centre) and lately because a lot of people got a notice, on the same day, that they were rejected, and stuff like that changes the interaction, some days there are a lot of interviews (as a part of their application), some days it is really hard and people don't want to do anything, people had a bad day or the food was bad, and many things can change the interaction (between volunteers and the asylum seekers). (Stig)

Throughout the interview, Stig stressed that many of the asylum seekers are in a limbo: they cannot start a life as they are waiting for a decision. The waiting time to process the asylum application can take years, and asylum seekers can also be moved from one centre to another. It seems that daily life is taken away from them, as the waiting time is marked by waiting, tension, and anxiety. The volunteers at the asylum centre thus aimed to create a context where both volunteers and asylum seekers interact through convivial practices, such as playing football, drawing, or having a cup of coffee.

Disseminating information and raising awareness for better communication in the society in order to enhance mutual understanding and tolerance brings in the non-communitarian aspect of convivial solidarity. The quote below is from Christina, who is running two different solidarity initiatives: one of them is legal assistance, the other one is an online archive about 
issues relating to refugees. She explains below the significance of disseminating information to the wider society, when she talks about the online archive that she created:

I quickly found out that most refugees and asylum seekers and even Danes, they don't understand the system at all. It is really complicated and it is made complicated on purpose actually, I think. It could be much easier to understand, and it could be used much more simply, it is very complicated, nobody understands it. Actually I found out that only a few lawyers really understand, (laughs) not even the politicians understand what they vote for or against sometimes, so I just decided to find out how things were working, understand the system. I am not a lawyer so I want to do it from the outside. I managed! (laughs). (...) I try to inform the Danish public about how complex the situation is, trying to make them understand that our laws are very cynical and not working as they should (...) and also trying to make the public understand that the refugees are not here for fun. It is not a choice they made, it is not something they do to make something out of it. They are just desperate and it is their only option. So I am trying to spread information to refugees themselves about their own situation, help them out of that and trying to make a better understanding among the public, and among the people who work with this in many ways like politicians and journalists to make them understand that it is not working as it should, and we could make it much better and things are really not fair as they are. (Christina)

As Christina sees it, the problems and issues mentioned above are not only the refugees' concern, but concern all people living in Denmark. In her view, everyone, not only refugees or asylum seekers but anyone who lives in Denmark, needs the information on asylum laws, system, and conditions of the asylum seekers. The wider society should know about the issues that the refugees face, the Danish asylum system, and its complexities, so that one can fight the anti-migrant and communitarian rhetoric and the unwelcoming attitude that one can find in the politicians' claims and in some societal responses in Denmark. Most of the organisations, as reflected in the quantitative results, disseminate information because they would like to raise awareness on the difficulties refugees and migrants face, the conditions at the asylum centres and the continuous legal restrictions from the Danish governments that make migration and asylum rules tighter and tighter.

Convivial solidarity is not only about daily activities, forming relations, and face-to-face interaction; it also has political and legal dimensions. Some 
of my interviewees stated that convivial practices in the form of face-to-face social interaction are not enough. They highlighted the political focus of their organisation or, as Christina quoted above, give priority to securing the asylum seekers' and refugees' legal rights. Christina further articulated that only engaging in social activities is not enough to support refugees; one must help them in legal matters:

The main problem that asylum seekers have, also refugees to a certain degree, that is the permit to stay, the papers. That is like the core of everything else. In my view, it did not make sense to do a social visit, and maybe to bring them out of the camp, to take a walk or drink tea, listen to their story or try to help those children, to bring used toys and things like that, it was not that important compared to that huge issue, which was waiting for the decision or already having a negative decision and worrying about their future and what to do. (...) It is mainly legal assistance and guidance and practical help that we offer. (Christina)

The quote above articulates the limitations of convivial practices, by stating that doing social activities, having tea or coffee, interacting with the asylum seekers will not solve the legal issues of the asylum seekers, which are seen as crucial. Everybody needs 'the papers', a resident permit, to have access to the civic rights, to start and to be able to create a daily life in Denmark. For this reason, Christina prioritises the offering of legal advice to the asylum seekers, refugees, and migrants in general.

Within some organisations, convivial solidarity is performed as a political fight for justice, equality, and for providing legal rights to the asylum seekers. Annika is an activist and a member of a protest group formed of elderly people; her quote below points to the normative aspect of convivial solidarity. Her group challenges and opposes the government in order to change migration laws, improve the conditions at asylum centres, and inform the Danish public about what is going on there. Annika explained how and why they started their protest group:

It (their aim to start the protest group) was to put attention to the society, to the government, of conditions of particular children in the centre, because people (Danes) did not know this, and they think that Denmark, they (Danes) are very open, human, they, when we have signed these (UN) conventions of course we keep them. Year after year, it has been proved, no. When it comes to children of refugees, we (Danes) are not keeping them (Danes do not apply the UN conventions). And even today, this summer, we could 
confront some politicians in the folk meeting in Bornholm, they want to change conventions but not the child conventions, (...) and then we said 'hey, it is for all children, for Danish children, for refugees' children, asylum seekers, children coming here without their parents. How can you make law, for example, the education of the refugee children is not similar to the education of the Danish children are having?” (Annika)

In this quote, Annika stresses that 'children are children' no matter whether they are Danes or refugees or asylum seekers. She points out that asylum children should be offered the same education opportunities as the Danish children. She has a non-communitarian approach when it comes to the education of children, and she does not differentiate between the native/Danish or the refugee/asylum seeker/migrant child: children are children. She explains how the long periods of waiting and being moved from one centre to another affect the children's learning. Annika and those in her organisation/protest group regularly visit the asylum centres to learn about the conditions, and how the asylum seekers feel about them. Some of the members are guardians ${ }^{7}$ of the children who have no parents. The convivial solidarity that they engage in has a political aim. In order to achieve political change in terms of better asylum centre conditions and migration laws, they protest on the street, write letters to newspapers and politicians, and attend the People's meeting (Folkemødet), which is a platform where politicians meet and debate with the citizens once a year in Bornholm. This political fight is an enactment of convivial solidarity; it is a fight for conviviality. It is fight for the asylum seekers, families, and children to gain an equal status and place in the Danish society, to be able to start a convivial life by being educated in Danish, by leaving the asylum centres and building social relations with people living in Denmark.

\section{Concluding Remarks}

In this chapter, I told the story of how I constructed the concept of convivial solidarity, by presenting my analytical journey from research on conviviality and diversity in Istanbul, to solidarity activities with the migrants and refugees living in Denmark. This chapter glimpsed at what goes behind the stage when we, as researchers, revise analytical concepts and see the need for constructing new ones.

In summary, convivial solidarity is oriented towards daily life and social interactions between people without putting boundaries between groups, 
and instead stressing what unites people, what they share as humans, their common fights and concerns. This resonates with Glick Schiller's description of cosmopolitan sociability not as tolerance of differences, but as the 'domains of commonality' that make people sociable (Glick Schiller, Darieva, and Gruner-Domic 2011). Nonetheless, convivial solidarity is not limited to social interactions but also has political and legal grounding. It sprouts from and grows with tensions at critical times, uniting and bonding the people engaged in solidarity activities. Can convivial solidarity as a concept be useful to explore a range of initiatives that support the incoming refugees to Europe? What are the limitations of this concept? Does it refer to only temporary solidarity or will it be useful for understanding the conviviality that may develop in the long-term, regarding the settlement, adaptation and inclusion of the refugees in Denmark and elsewhere? Can it be expanded to other civil society initiatives? Further research can try to explore these questions.

\section{Notes}

1. In this chapter, I leave out cosmopolitanism and super-diversity all together and focus on conviviality.

2. France, Denmark, Greece, Poland, Germany, the UK, Switzerland, and Italy.

3 . This chapter presents only the data that concerns migrants and refugees.

4. The interviews were conducted in English, and to ensure clarity, grammatical mistakes were corrected.

5. Danish Migration Agency for the statistics: https://www.nyidanmark.dk/ da/Tal-og-statistik/Tal-og-fakta, accessed June 17, 2019.

6. Danish civil society has a hybrid structure, where state institutions work together with civil societies (Fehsenfeld and Levinsen 2019). Especially during the peak time of the arrivals of the refugees in 2015, many municipalities relied on collaboration with refugee civil society organisations and volunteers, ranging from welcoming them, providing basic needs and helping in their registration, as well as providing Danish language classes. This was also the case in the asylum centres, where civil society organisations support the asylum seekers, such as the one mentioned in the quote.

7. To be a guardian of a child means to accept to fulfil the duties of a parent in taking care of a child. 


\section{REFERENCES}

Akgönül, S. 2007. Türkiye Rumları: ulus-devlet çağından küreselleşme çağına bir azınliğrn yok oluşu süreci. Istanbul: İletişim.

Bruni, L. 2008. Reciprocity, Altruism and the Civil Society. London: Routledge.

Chau, A. Y. 2008. "The Sensorial Production of the Social." Ethnos: Journal of Anthropology 73 (4): 485-504. https://doi.org/10.1080/ 00141840802563931.

Cowan, J. K. 2006. "Culture and Rights After Culture and Rights." American Anthropologist 108 (1): 9-24.

Dayton, B. W., and L. Kriesberg. 2009. Conflict Transformation and Peacebuilding: Moving from Violence to Sustainable Peace, Security and Conflict Management. Abingdon and New York: Routledge.

Duru, N. D. 2013. "Coexistence and Conviviality in Multi-Faith, Multi-Ethnic Burgazadasi, the Princes' Islands of Istanbul.” PhD diss., University of Sussex.

Duru, D. N. 2015. "From Mosaic to Ebru: Conviviality in Multi-Ethnic, MultiFaith Burgazadas1, Istanbul.” South European Society \& Politics 20 (2): 243-263. https://doi.org/10.1080/13608746.2015.1047080.

Duru, D. N. 2016. Memory, Conviviality, and Coexistence: Negotiating Class Differences in Burgazadasi, Istanbul, Space and Place. New York: Berghahn Books.

Duru, D. N., T. Spejlborg Sejersen, and H. J. Trenz. 2016. "Denmark." In Integrated Report on Reflective Forms of Transnational Solidarity: Innovative Practices of Transnational Solidarity at Times of Crisis, edited by Maria Kousis, Christian Lahusen, and Angelos Loukakis, 129-146.

Duru, D. N., T. Spejlborg Sejersen, and H. J. Trenz. 2018. "Solidarity in Times of Crisis: Disability, Immigration and Unemployment in Denmark.” In Solidarity as a Public Virtue? 249-274. Baden-Baden: Nomos Verlagsgesellschaft mbH \& Co. KG.

Eriksen, T. H. 2001. "Between Universalism and Relativism: A Critique of the UNESCO Concept of Culture." In Culture and Rights: Anthropological Perspectives, edited by J. K. Cowan, M. Dembour, and R. A. Wilson, 127-148. Cambridge: Cambridge University Press.

Federico, V., and Lahusen, C., eds. 2018. Solidarity as a Public Virtue?: Law and Public Policies in the European Union. Baden-Baden: Nomos Verlagsgesellschaft $\mathrm{mbH}$.

Fehsenfeld, M., and K. Levinsen. 2019. "Taking Care of the Refugees: Exploring Advocacy and Cross-Sector Collaboration in Service Provision for Refugees." Voluntas: International Journal of Voluntary and Nonprofit Organizations 30 (2): 422-435. https://doi.org/10.1007/s11266-019-00097-5.

Gammeltoft-Hansen, T. 2017. "Refugee Policy as 'Negative Nation Branding': The Case of Denmark and the Nordics." Danish Foreign Policy Yearbook, 99-125. 
Gidron, B., S. N. Katz, and Y. Hasenfeld. 2002. Mobilizing for Peace: Conflict Resolution in Northern Ireland, South Africa, and Israel/Palestine. Oxford Scholarship Online. New York: Oxford University Press.

Glick Schiller, N. 2016. "The Question of Solidarity and Society: Comment on Will Kymlicka's Article: 'Solidarity in Diverse Societies'." Comparative Migration Studies 4 (1): 6. https://doi.org/10.1186/s40878-016-0027-x.

Glick Schiller, N., T. Darieva, and S. Gruner-Domic. 2011. "Defining Cosmopolitan Sociability in a Transnational Age: An Introduction." Ethnic and Racial Studies 34 (3): 399-418.

Grillo, R. 2007. "An Excess of Alterity? Debating Difference in a Multicultural Society." Ethnic and Racial Studies 30 (6): 979-998. https://doi.org/10.1080/ 01419870701599424.

Güven, D. 2006. Cumburiyet Donemi Azinlik Politikalari ve Stratejileri Baglaminda 6-7 Eylul Olaylari. Istanbul: Iletisim Publishers.

Hannerz, U. 1990. "Cosmopolitans and Locals in World Culture." Theory, Culture \& Society 7 (2-3): 237-251. https://doi.org/10.1177/ 026327690007002014.

Henrik, C., M. Beyeler, R. Eichenberger, P. Nannestad, and M. Paldam. 2013. The Good Society: A Comparative Study of Denmark and Switzerland. Berlin: Springer.

Hirschon, R. 2003. Crossing the Aegean: An Appraisal of the 1923 Compulsory Population Exchange Between Greece and Turkey. Studies in Forced Migration, 12: New York and Oxford: Berghahn.

Jeffries, V. 2014. The Palgrave Handbook of Altruism, Morality, and Social Solidarity: Formulating a Field of Study. New York: Palgrave.

Joppke, C., and S. Lukes. 1999. Multicultural Questions. Oxford: Oxford University Press.

Jöhncke, S. 2011. “Integrating Denmark: The Welfare State as a National(ist) Accomplishment." In The Question of Integration: Immigration, Exclusion and the Danish Welfare State, edited by K. F. Olwig and K. Paerregaard, 30-53. Newcastle upon Tyne: Cambridge Scholars Publishing.

Kuyucu, A. T. 2005. "Ethno-Religious 'Unmixing' of 'Turkey': 6-7 September Riots as a Case in Turkish Nationalism." Nations and Nationalism 11 (3): 361380. https://doi.org/10.1111/j.1354-5078.2005.00209.x.

Kymlicka, W. 1995. Multicultural Citizenship. Oxford: Clarendon Press.

Overing, J., and A. Passes. 2000. The Anthropology of Love and Anger: The Aesthetics of Conviviality in Native Amazonia. London: Routledge.

Phillips, D. L. 1996. "Comprehensive Peace in the Balkans: The Kosovo Question." Human Rights Quarterly 18 (4): 821. https://doi.org/10.1353/hrq.1996. 0048.

Ring, L. A. 2006. Zenana: Everyday Peace in a Karachi Apartment Building. Bloomington and Indianapolis: Indiana University Press. 
Taylor, C. 1992. Multiculturalism: Examining the Politics of Recognition. Edited by Amy Gutmann. Princeton: Princeton University Press.

Todorova, M. N. 1997. Imagining the Balkans. New York: Oxford University Press.

Valluvan, S. 2016. "Conviviality and Multiculture: A Post-integration Sociology of Multi-Ethnic Interaction." Young 24 (3): 204-221. https://doi.org/10. $1177 / 1103308815624061$.

Vertovec, S. 2007. "Super-Diversity and Its Implications." Ethnic and Racial Studies 30 (6): 1024-1054. https://doi.org/10.1080/01419870701599465.

Weiss, R., and P. Peres. 2014. "Beyond the Altruism-Egoism Dichotomy: A New Typology to Capture Morality as a Complex Phenomenon." In The Palgrave Handbook of Altruism, Morality, and Social Solidarity, edited by V. Jeffries, 7197. New York: Palgrave.

Open Access This chapter is licensed under the terms of the Creative Commons Attribution 4.0 International License (http://creativecommons.org/licenses/by/ $4.0 /$ ), which permits use, sharing, adaptation, distribution and reproduction in any medium or format, as long as you give appropriate credit to the original author(s) and the source, provide a link to the Creative Commons license and indicate if changes were made.

The images or other third party material in this chapter are included in the chapter's Creative Commons license, unless indicated otherwise in a credit line to the material. If material is not included in the chapter's Creative Commons license and your intended use is not permitted by statutory regulation or exceeds the permitted use, you will need to obtain permission directly from the copyright holder.

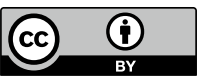

